\title{
PERANCANGAN DESAIN CHATBOT BERDASARKAN PERENCANAAN ARSITEKTUR ENTERPRISE MENGGUNAKAN TOGAF ADM
}

\author{
Surya Jaya Raka ${ }^{1}$, Andi Wahju Rahardjo Emanuel ${ }^{2}$ \\ 1,2 Magister Informatika, Universitas Atma Jaya Yogyakarta \\ Jalan Babarsari No 44 Yogyakarta 55281 \\ Iandi.emanuel@uajy.ac.id, ${ }^{2}$ suryajayaraka@gmail.com
}

\begin{abstract}
Abstrak- Gapura Studio merupakan salah satu pengembang aplikasi dan konsultan teknologi yang ada di Kota Yogyakarta. Sebagai pengembang aplikasi, perusahaan ini menjual produk nya melalui website yang dimiliki (online). Gapura Studio merasa bahwa performa website yang dimiliki kurang baik sehingga berpengaruh dengan proses bisnis salah satu nya adalah kurangnya interaksi di website yang mengakibatkan minim nya pengguna yang melakukan order. Dalam penelitian ini mencoba menyelesaikan permasalahan tersebut dengan menambah interaksi di website Gapura Studio dengan terlebih dahulu membuat arsitektur enterprise perusahaan. Penelitian ini menghasilkan blueprint pengembangan sistem informasi manajemen perusahaan dan berhasil mengembangkan fitur chatbot yang harapan nya mampu menjadi solusi permasalahan awal website Gapura Studio dengan menambahkan interaksi berupa chatbot berdasarkan proses bisnis yang dijabarkan dalam proses perancangan arsitektur enterprise untuk mengatasi permasalahan interaksi pada website Gapura Studio.
\end{abstract}

Kata Kunci- TOGAF ADM, Enterprise Architecture, Chatbot, Website

Abstract-Gapura Studio is one of the application developers and technology consultants in Yogyakarta City. As an application developer, this company sells its products through its website (online). Gapura Studio feels that its website performance is not good enough that it affects business processes, one of which is the lack of interaction on the website which results in minimal users placing orders. In this study, trying to solve this problem by increasing the interaction on the Gapura Studio website by first creating the company's enterprise architecture. This research produces a blueprint for the development of a company management information system as well as a chatbot design based on a business process that is described in the process of designing an enterprise architecture to solve interaction problems on the Gapura Studio website.

Keywords - TOGAF ADM, Enterprise Architecture, Chatbot, Website

\section{PENDAHULUAN}

Teknologi informasi yang terus mengalami perkembangan membuat beberapa perusahaan mulai mengembangkan peran bisnis yang mengikuti perkembangan teknologi informasi ini. Terjadi berbagai penyesuaian yang harus dilakukan oleh perusahaan untuk menyesuaikan perkembangan tersebut. Teknologi informasi yang banyak digunakan oleh perusahaan untuk menunjang proses bisnis saat ini adalah website. Situs website harus menyediakan konten yang sesuai dengan yang diharapkan oleh pengguna. Hal ini menjadi factor penting yang akan diperhatikan oleh pengguna [1]. Website mampu menjadi tempat penyampaian informasi perusahaan hingga produk kepada klien maupun masyarakat luas.

Ribuan website telah terpublikasi di jagad internet dan berbagai metriks penilaian performa website juga beragam untuk menilai sebuah website. Salah satu nya adalah metriks bounce rate yang sering dijumpai seorang analis website menggunakan platform analytic.
Bounce rate mewakili tolok ukur yang signifikan untuk penilaian nilai keterlibatan interaksi yang di berbagai konten dalam website [2]. Ini yang menjadi permasalahan sebuah website karena metriks ini mampu menunjukkan seberapa banyak pengguna berinteraksi dengan website. Semakin tinggi nilai bounce rate maka sedikit pengguna yang berinteraksi dengan website. Hal ini tentunya sangat buruk karena mengindikasikan sedikit pula yang melakukan klik atau interaksi lainnya hingga tertarik untuk akhirnya membeli suatu produk atau jasa yang ditawarkan di website. Permasalahan tingginya bounce rate ini juga yang dialami website Gapura Studio sebagai pengembang aplikasi dan konsultan teknologi. Gapura Studio membutuhkan penambahan interaksi di website agar nilai metriks bounce rate dapat diturunkan dalam kurun waktu tertentu. Tentu perlu dilakukan perencanaan penambahan interaksi yang sesuai dengan kebutuhan sehingga mampu menunjang proses bisnis Gapura Studio. 
Berbagai fitur dapat ditampilkan di website sebagai informasi utama hingga fitur pendukung agar website memberikan interaksi dan informasi kepada pengguna. Interaksi tersebut dapat berupa katalog, keranjang pembelian hingga pembayaran produk. Selain fitur utama tersebut, salah satu fitur yang dapat menunjang proses tersebut adalah fitur Chatbot. Fitur Chatbot adalah sebuah pengembangan fitur percakapan yang mampu memberikan interaksi kepada pengguna pada topik atau domain tertentu [3]. Chatbot ini mampu berinteraksi meliputi percakapan menggunakan input teks yang dimasukkan oleh pengguna atau pemilihan tombol yang berisi knowledge yang sudah dirancang sesuai kebutuhan. Chatbot biasanya mengikuti seperangkat aturan atau alur yang ditetapkan untuk menanggapi pertanyaan yang diajukan oleh pengguna. Walau bukan merupakan fitur utama dalam website namun chatbot sebenarnya mampu memberikan kontribusi besar dalam interaksi website khususnya untuk meningkatkan nilai bisnis.

Perancangan chatbot selalu berdasarkan dengan riset yang telah dilakukan sebelumnya. Knowledge yang dirancang pada chatbot berupa informasi yang paling dibutuhkan pengguna agar pengguna mampu mendapatkan informasinya secara cepat dan sesuai dengan teks ataupun permintaan yang di masukan berdasarkan knowledge yang ada serta sesuai dengan visi dan misi perusahaan demi meraih target yang telah ditentukan. Hal ini dapat dilakukan dengan terlebih dahulu membuat arsitektur enterprise perusahaan terlebih dahulu untuk dapat secara utuh memahami kebutuhan atau target perusahaan. Arsitektur enterprise adalah alat yang dapat digunakan untuk membangun keselarasan antara TI dengan bisnis organisasi [4]. Perancangan yang dilakukan perlu riset mendalam sehingga knowledge yang dimasukkan pada chatbot sesuai dengan kebutuhan. Penelitian ini dilakukan untuk merancang fitur chatbot sesuai dengan kebutuhan Gapura Studio sehingga mampu menunjang proses bisnis dan meningkatkan performa website Gapura Studio. Penelitian ini akan melakukan perancangan chatbot yang dilakukan dengan perencanaan arsitektur enterprise terlebih dahulu menggunakan framework TOGAF ADM hingga menghasilkan blueprint perancangan chatbot yang sesuai dengan kebutuhan.

\section{TINJAUAN PUSTAKA}

Penelitian ini mengacu pada beberapa penelitian yang sebelumnya telah dilakukan. Pertama adalah penelitian yang menghasilkan cetak biru atau blueprint untuk perancangan arsitektur enterprise. Pembuatan cetak biru atau blueprint adalah tujuan dari perancangan arsitektur enterprise yang telah dilakukan. Dalam perencanaan arsitektur enterprise Universitas Pasifik (UNIPAS) Morotai menggunakan metode TOGAF ADM seperti yang akan dilakukan penulis dalam penelitian ini. TOGAF ADM merupakan kerangka atau metode yang digunakan untuk mengembangkan arsitektur enterprise atau sebuah sistem [4]. Pada penelitian tersebut murni menggunakan kerangka kerja TOGAF ADM tanpa menggabungkan dengan metode atau kerangka kerja lainnya.

Berbeda dengan penelitian yang berjudul Designing an Enterprise Architecture Government Organization Based on TOGAF ADM and SONA yang menggabungkan TOGAF ADM dengan ServiceOriented Network Architecture (SONA) dalam perancangan arsitektur enterprise [5]. Tahap yang dilakukan dalam penelitian di UNIPAS ini adalah preliminary untuk menggambarkan ruang lingkup dan kondisi di UNIPAS. Lalu Vision Architecture digunakan untuk menggambarkan perencanaan arsitektur agar dapat memenuhi tujuan strategis. Kemudian business architecture dan information system architecture yang masing-masing untuk memberikan gambaran proses bisnis dan memodel kan arsitektur aplikasi yang akan dikembangkan. Penelitian ini menghasilkan blueprint arsitektur yang harapannya mampu memberikan perbaikan dalam pelayanan di UNIPAS. Sama dengan penelitian ini, penelitian yang dilakukan oleh Silvia Dwi Oktatila dkk [6] juga membahas perencanaan arsitektur sistem. Hasil penelitian ini didapatkan hasil akhir berupa blueprint yang terdiri dari arsitektur bisnis, arsitektur aplikasi, arsitektur data, dan arsitektur teknologi.

Selanjutnya adalah penelitian yang dilakukan oleh Albert Yakobus Chandra dkk [7]. Dalam memberikan pelayanan kepada konsumen, pelaku UMKM selalu mendapatkan pertanyaan terkait informasi hingga pembelian produk. Informasi yang ditanyakan biasanya memiliki kebiasaan yang sama sehingga membutuhkan jawaban yang sama. Penelitian ini mengembangkan chatbot untuk mengatasi masalah tersebut. Chatbot yang dikembangkan menggunakan tools Diagflow. Ini merupakan platform untuk membuat bot, dimana platform ini mencocokkan kata dari request user. Selanjutnya akan diolah oleh Agent lalu memberikan umpan balik kepada user dengan response dan output data dengan format JSON. Metode yang digunakan dalam pengembangan chatbot ini adalah menggunakan model waterfall. Model ini merupakan salah satu model yang digunakan dalam pengembangan perangkat lunak dalam model SDLC (Software Development Life Cycle) yaitu dengan langkah requirement analyst, system design, implementation, verification/testing, maintenance [8].

Dalam penelitian lainnya menyebutkan bahwa penyampaian informasi melalui chatbot mampu mengefektifkan waktu bagi petugas maupun pihak terkait sehingga dengan adanya chatbot mampu mengurangi kerugian waktu yang cukup banyak [9]. Penelitian yang dilakukan oleh Maskur ini mengimplementasikan chatbot menggunakan ALICE (Artificial Linguistic Internet Computer Entity) yang merupakan framework chatbot yang sedang berkembang saat ini. Penelitian ini lebih banyak melakukan pembuatan flowchart untuk daftar 
pertanyaan dan knowledge yang menjadi keluaran chatbot. Proses dilakukan mulai dari pengumpulan dan analisa data hingga pengujian fungsional sistem.

Chatbot dapat digunakan dalam berbagai situasi yang mendukung jalannya fitur dalam sebuah sistem. Dalam penelitian terdahulu yang telah dilakukan oleh Ruspandi R., dkk menggunakan chatbot sebagai helpdesk pada sistem terpadu yang di gunakan Universitas Sam Ratulangi. Penelitian ini akan mengembangkan chatbot bertipe Question Answering yang artinya akan memberikan bantuan kepada pengguna berupa jawaban dari pertanyaan. Pengembangan chatbot yang dilakukan dalam penelitian ini mengimplementasikan Algoritma Bigram. Algoritma ini merupakan sepasang unit tertulis yang berurutan bias berupa huruf, kata, dan suku kata [10].

Selanjutnya penelitian yang ditulis ini akan mengadopsi beberapa metode dalam penelitian yang telah dilakukan sebelumnya. Namun berbeda dalam penelitian sebelumnya, dalam penelitian ini penulis mencoba untuk melakukan perancangan fitur website seperti yang menjadi permasalahan website Gapura Studio dengan mengacu pada arsitektur enterprise perusahaan yang dirancang menggunakan TOGAF ADM. Penelitian ini mencoba membuat fitur chatbot yang sesuai dengan visi perusahaan dan pelayanan terhadap calon pelanggan atau pengguna website.

\section{METODOLOGI}

Dalam penelitian ini akan menghasilkan cetak biru atau blueprint arsitektur enterprise dan perancangan fitur chatbot yang mengacu pada arsitektur enterprise Gapura Studio yang dikembangkan menggunakan TOGAF ADM. Pendekatan yang dilakukan berdasarkan dengan kondisi dan permasalahan yang dihadapi Gapura Studio dalam menjalankan bisnis. Pengumpulan data dilakukan dengan melakukan wawancara dengan pemilik perusahaan dengan metode kerangka kerja TOGAF ADM. Seperti dalam penelitian yang menjadi acuan penulis, proses atau tahapan perencanaan menggunakan TOGAF ADM hanya menggunakan empat tahapan yaitu Architecture Vision, Business Architecture, Information System Architecture, dan Information System Architecture (Tahap A - C) seperti pada Gambar 1 berikut:

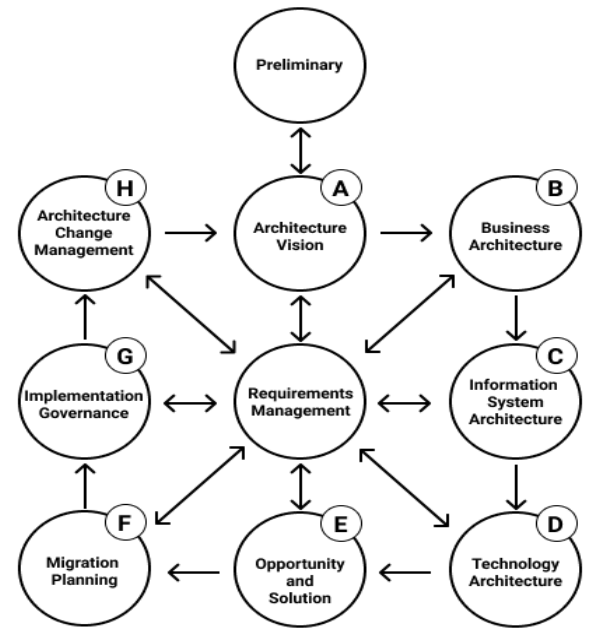

Gbr. 1 Tahap dalam kerangka kerja TOGAF ADM

\section{A. Preliminary}

Tahap ini digunakan untuk melakukan identifikasi kondisi dan proses bisnis untuk memenuhi kerangka arsitektur organisasi, spesifikasi, dan prinsip organisasi [11]. Proses ini tentunya akan dilakukan berhubungan terhadap perusahaan Gapura Studio. Tujuan utamanya adalah untuk memberikan keyakinan kepada setiap orang yang terlibat didalamnya bahwa kerangka kerja ini mampu memberikan kesuksesan dalam perencanaan arsitektur enterprise.

\section{B. Architecture Vision}

Tahap ini berguna untuk melakukan keseragaman pandangan untuk menerapkan pengembangan arsitektur menggunakan TOGAF ADM sesuai dengan kendala dan harapan yang ditetapkan [12]. Pada tahap ini tujuannya untuk menghasilkan visi arsitektur yang sesuai dengan kebutuhan.

\section{Business Architecture}

Di tahap business architecture ini berisi tentang strategi bisnis yang sedang berjalan dan informasi aktivitas yang dilakukan [13]. Dengan informasi tersebut maka dapat dirancang arsitektur bisnis yang untuk mendukung visi arsitektur yang sudah ditetapkan sebelumnya.

\section{Information System Architecture}

Dalam tahap ini dilakukan pemodelan atau rancangan sistem informasi yang disesuaikan pada tahap-tahap sebelumnya [14]. Bagian ini menekankan aktivitas pengembangan arsitektur sistem informasi.

\section{IV.HASIL DAN DISKUSI}

Hasil dan pembahasan pemodelan arsitektur enterprise dengan menggunakan kerangka kerja TOGAF ADM sebagai acuan pengembangan blueprint 
fitur chatbot untuk meningkatkan performa website Gapura Studio adalah sebagai berikut:

\section{A. Preliminary}

Pada tahapan ini penulis menggambarkan kondisi

Page|203 yang ada saat ini di perusahaan Gapura Studio. Perusahaan ini merupakan salah satu perusahaan yang bergerak dibidang pengembangan perangkat lunak dan konsultan teknologi yang berada di Kota Yogyakarta. Gapura Studio berada di dalam CV. Gapura Solusi Digital yang mulai beroperasi tahun 2019 sehingga dapat disebut sebagai start-up. Perusahaan start-up adalah usaha bisnis baru yang dibuat dari nol yang sebelumnya tidak ada.

Berdasarkan data yang berhasil didapatkan penulis melalui wawancara dengan pemilik perusahaan bahwa ada permasalahan terkait performa website perusahaan yang berasal dari kegagalan perusahaan mengkomunikasikan proses bisnis atau produk kepada pengguna website. Hal ini karena kegagalan dalam memanfaatkan fitur atau teknologi dalam website perusahaan. Dari permasalahan ini ditemukan bahwa perusahaan tidak melakukan pendefinisian terhadap aktivitas perusahaan sehingga dalam tahap ini penulis akan mendefinisikan aktivitas perusahaan. Ada beberapa aktivitas utama dan pendukung yang berhasil penulis dapatkan dari hasil wawancara yang dapat dijadikan acuan dalam perancangan arsitektur enterprise seperti pada Gambar 2 dan Gambar 3 berikut ini:

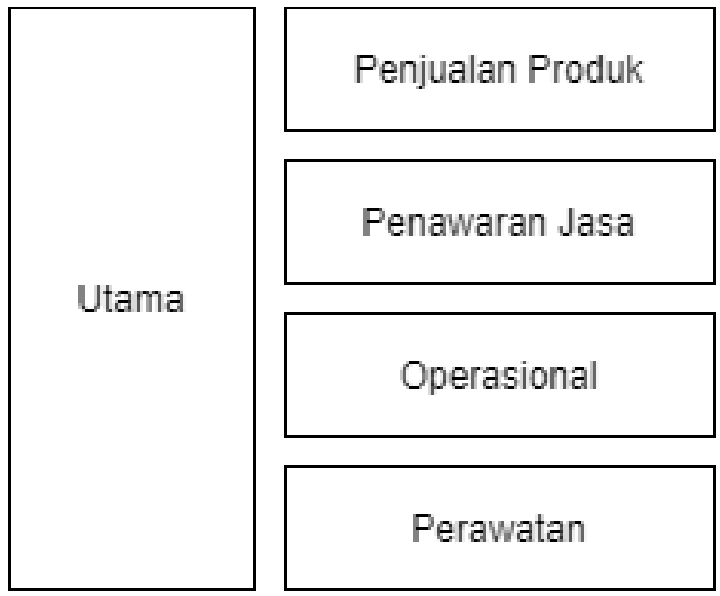

Gbr. 2 Aktivitas Utama Perusahaan

1) Penjualan Produk, merupakan kegiatan inti dari perusahaan yaitu menjual software yang telah dikembangkan kepada pelanggan. Produk yang dimiliki Gapura Studio ada lima yaitu Sistem Informasi Akademik (SIAKAD), Sistem Informasi Manajemen Rumah Sakit (SIMRS), Sistem Perpustakaan (SIPUS), SIMU (Sistem Informasi Manajemen UMKM), dan Company Website. Masing-masing produk memiliki dua jenis paket yang memiliki perbedaan mendasar dari sisi fitur dan harga yang di tawarkan.
2) Penawaran jasa, adalah aktivitas yang diperlukan untuk perusahaan mendapatkan revenue dengan menawarkan jasa pengembangan aplikasi sesuai kebutuhan pelanggan dan konsultan teknologi.

3) Operasional, merupakan kegiatan yang penting dalam fase pengembangan aplikasi. Kegiatan ini merupakan siklus pembuatan aplikasi atau sistem yang harus di dokumentasikan seluruh prosesnya.

4) Perawatan, merupakan kegiatan pasca aplikasi atau sistem telah di implementasikan dan digunakan pelanggan.

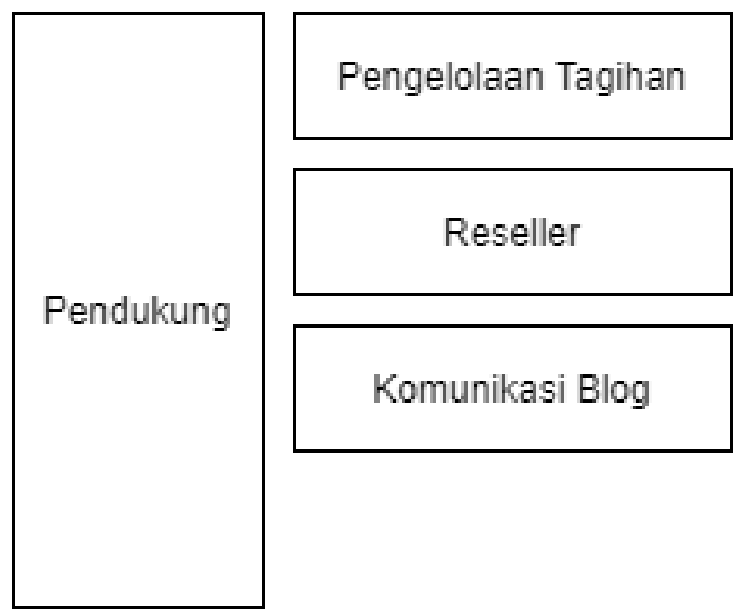

Gbr. 3 Aktivitas Pendukung Perusahaan

1) Pengelolaan Tagihan, merupakan aktivitas pendukung yang juga penting untuk diperhatikan. Kegiatan ini untuk memberikan pelanggan tagihan sebelum atau setelah projek dikerjakan.

2) Reseller, merupakan proses menjual kembali produk kepada konsumen melalui pihak kedua sehingga reseller bukanlah produsen melainkan hanya menjual barang yang diproduksi oleh pihak kedua [15]. Dalam hal ini Gapura Studio membutuhkan proses marketing semacam ini untuk menjangkau lebih banyak pelanggan.

3) Komunikasi Blog atau Portal Berita, website membutuhkan konten-konten baru untuk dipublikasikan kepada pengguna website. Berita merupakan keterangan atau narasi tentang sesuatu yang baru saja terjadi atau yang lampau terjadi.

\section{B. Architecture Vision}

Untuk mendapatkan keseragaman dalam pandangan arsitektur, maka perlu di definisikan lebih detail. Visi utama dalam perencanaan arsitektur ini adalah "menyediakan sistem informasi yang aman, mudah digunakan, dan adaptif untuk meningkatkan performa website Gapura Studio". Detail visi arsitektur dapat dilihat pada tabel 1 dibawah ini: 
TABEL 1

VISI ARSITEKTUR

\begin{tabular}{|c|c|c|}
\hline No & Jenis & Visi \\
\hline 1 & Arsitektur Bisnis & $\begin{array}{l}\text { Dapat menjadi jembatan } \\
\text { untuk memberikan pelayanan } \\
\text { kepada pengguna website } \\
\text { sehingga mereka dapat } \\
\text { berinteraksi secara aktif dan } \\
\text { meningkatkan kemungkinan } \\
\text { order hingga meningkatkan } \\
\text { revenue. Selain itu dapat } \\
\text { meningkatkan pelayanan } \\
\text { kepada pelanggan. }\end{array}$ \\
\hline 2 & Arsitektur Data & $\begin{array}{l}\text { Memberikan } \\
\text { menggunakan data yang } \\
\text { akurat dan terbaru kepada } \\
\text { pelanggan serta terjamin } \\
\text { keamanannya. }\end{array}$ \\
\hline 3 & $\begin{array}{l}\text { Arsitektur } \\
\text { Aplikasi }\end{array}$ & $\begin{array}{lr}\text { Mengembangkan } & \text { sistem } \\
\text { informasi yang mampu } & \text { mas } \\
\text { menjadikan proses } & \text { bisnis } \\
\text { maupun manajemen menjadi } & \text { mefif dan efisien }\end{array}$ \\
\hline 4 & $\begin{array}{l}\text { Arsitektur } \\
\text { Teknologi }\end{array}$ & $\begin{array}{l}\text { Mendistribusikan } \\
\text { infrastruktur IT yang } \\
\text { mendukung kebutuhan } \\
\text { pelanggan dan infrastruktur } \\
\text { TI disediakan dengan } \\
\text { menggunakan pendekatan } \\
\text { hemat biaya rerta } \\
\text { memberikan fitur website } \\
\text { yang mampu meningkatkan } \\
\text { interaksi pengguna. }\end{array}$ \\
\hline
\end{tabular}

\section{Business Architecture}

\section{Penjualan Produk}

Proses penjualan produk merupakan proses yang penting untuk mendapatkan pelanggan. Proses ini memiliki alur yang menggabungkan aktivitas pengguna website, customer care, manajemen, dan tim pengembangan. Pengelompokan aktivitas penjualan produk dapat dilihat pada tabel 2 dibawah ini:

TABEL 2

PROSES BISNIS PENJUALAN PRODUK

\begin{tabular}{|c|c|c|}
\hline No & Stakeholder & Aktivitas \\
\hline 1 & User & $\begin{array}{l}\text { - } \text { Mengunjungi website. } \\
\text { - Memilih produk atau jasa. } \\
\text { - Melihat fitur dan detail } \\
\text { produk } \\
\text { - } \text { Memberikan detail } \\
\text { kebutuhan } \\
\text { - } \text { Pembayaran uang muka }\end{array}$ \\
\hline 2 & Customer Care & 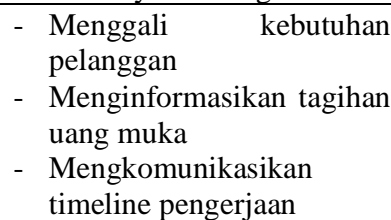 \\
\hline 3 & Manajemen & $\begin{array}{l}\text { - Melakukan konfirmasi } \\
\text { kebutuhan dan harga }\end{array}$ \\
\hline
\end{tabular}

\begin{tabular}{|l|l|lr|}
\hline 4 & Tim & - Menyusun & kebutuhan \\
& Pengembang & $\begin{array}{l}\text { Menyusun } \\
\text { pengerjaan. }\end{array}$ & timeline \\
& & \\
\hline
\end{tabular}

\section{Penawaran Jasa}

Proses ini berguna untuk memberikan ruang kepada pengguna untuk membuat sistem atau aplikasi diluar produk yang ditawarkan oleh Gapura Studio. Proses yang dilakukan hampir sama hanya saja pengguna website tidak perlu memilih produk. Detail aktivitas dalam proses ini dapat dilihat pada tabel 3 dibawah ini:

TABEL 3

PROSES BISNIS PENAWARAN JASA

\begin{tabular}{|c|c|c|}
\hline No & Stakeholder & Aktivitas \\
\hline 1 & User & $\begin{array}{l}\text { - } \text { Mengunjungi website. } \\
\text { - } \text { Memberikan detail } \\
\text { kebutuhan. } \\
\text { - } \text { Pembayaran uang muka }\end{array}$ \\
\hline 2 & Customer Care & $\begin{array}{l}\text { - } \text { Menggali kebutuhan } \\
\text { pelanggan. } \\
\text { - Menginformasikan } \\
\text { tagihan. } \\
\text { - } \text { Mengkomunikasikan } \\
\text { timeline pengerjaan }\end{array}$ \\
\hline 3 & Manajemen & $\begin{array}{l}\text { - Melakukan konfirmasi } \\
\text { kebutuhan dan harga. }\end{array}$ \\
\hline 4 & $\begin{array}{l}\text { Tim } \\
\text { Pengembang }\end{array}$ & 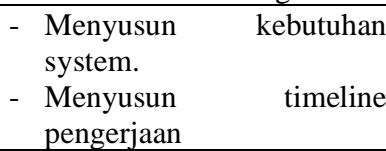 \\
\hline
\end{tabular}

3. Operasional

Proses operasional merupakan proses inti pengembangan aplikasi atau sistem yang harus di komunikasikan dengan pelanggan. Berikut aktivitas yang dilakukan pada proses operasional ini seperti pada tabel 4 dibawah ini:

TABEL 4

PROSES BISNIS OPERASIONAL

\begin{tabular}{|c|c|c|}
\hline No & Stakeholder & Aktivitas \\
\hline 1 & User & $\begin{array}{l}\text { - } \text { Konfirmasi kebutuhan. } \\
\text { - } \text { Review pengerjaan. } \\
\text { - } \text { Review revisi (opsional) } \\
\text { - } \text { Pembayaran Pelunasan }\end{array}$ \\
\hline 2 & Customer Care & $\begin{array}{ll}\text { - } & \begin{array}{l}\text { Menyiapkan } \\
\text { pelunasan. }\end{array}\end{array}$ \\
\hline 3 & Manajemen & - Konfirmasi produk final \\
\hline 4 & Tim Pengembang & 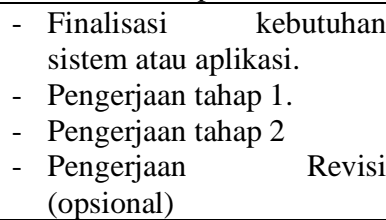 \\
\hline
\end{tabular}

\section{Perawatan}

Proses perawatan dapat dilakukan saat pelanggan memiliki kondisi yang perlu untuk dilakukan perbaikan. Untuk detail aktivitas dapat dilihat pada tabel 5 berikut: 
TABEL 5

PROSES BISNIS PERAWATAN

\begin{tabular}{|c|c|c|}
\hline No & Stakeholder & Aktivitas \\
\hline 1 & User & 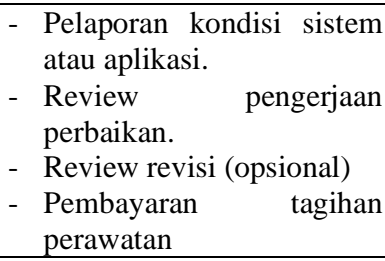 \\
\hline 2 & Customer Care & 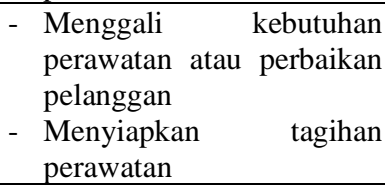 \\
\hline 3 & Manajemen & $\begin{array}{l}\text { - Konfirmasi kebutuhan } \\
\text { perawatan dan harga }\end{array}$ \\
\hline 4 & Tim Pengembang & $\begin{array}{llr}\text { - } & \text { Finalisasi kebutuhan } \\
& \text { perawatan atau perbaikan. } \\
\text { - } & \text { Pembuatan timeline } \\
\text { pengerjaan. } & \\
\text { - } & \text { Pengerjaan perawatan atau } \\
\text { perbaikan } & \\
\text { - } & \begin{array}{l}\text { Pengerjaan } \\
\text { (opsional) }\end{array} \\
\end{array}$ \\
\hline
\end{tabular}

\section{Business Architecture}

Untuk mewujudkan hubungan yang baik dan bersinergi dalam pelaksanaan proses bisnis maka perlu perencanaan sistem informasi atau aplikasi. Berikut rencana sistem informasi atau aplikasi yang akan menjadi blueprint untuk dikembangkan menjadi sistem seperti pada tabel 6 dibawah ini:

TABEL 6

ARSITEKTUR APLIKASI

\begin{tabular}{|c|l|}
\hline No & \multicolumn{1}{|c|}{ Sistem Informasi } \\
\hline 1 & Sistem informasi yang terdiri dari : \\
& - Fitur Penjualan Produk \\
& - Fitur Chatbot \\
& - Fitur LifeChat Penawaran Produk \\
& - Fitur Perawatan atau perbaikan \\
& - Fitur Blog atau Berita \\
\hline 2 & Sistem informasi manajemen yang terdiri dari : \\
& - Aplikasi Operasional \\
& - Aplikasi Pengajuan Perawatan atau Perbaikan \\
& - Aplikasi Tagihan \\
& - Aplikasi Reseller \\
\hline
\end{tabular}

Tabel diatas merupakan cetak biru atau blueprint pembuatan sistem yang diperlukan Gapura Studio. Namun dengan melihat cetak biru atau blue print tersebut dapat dilakukan pengembangan yang tepat berdasarkan kepentingan dan permasalahan utama Gapura Studio yaitu dengan pembuatan fitur untuk menambah interaksi pada website Gapura Studio untuk mengurangi tingkat bounce rate yang dihasilkan. Dengan begitu maka akan dibuat fitur chatbot yang mengacu pada data dan kebutuhan yang telah dijabarkan pada perencanaan arsitektur enterprise yang telah dilakukan. Chatbot diharapkan mampu menambah interaksi pengguna website Gapura Studio dan mampu mengarahkan pengguna website untuk melakukan pemesanan produk sehingga mampu meningkatkan revenue perusahaan. Berikut alur fitur chatbot pada salah satu penjualan produk seperti pada Gambar 4 dibawah ini:

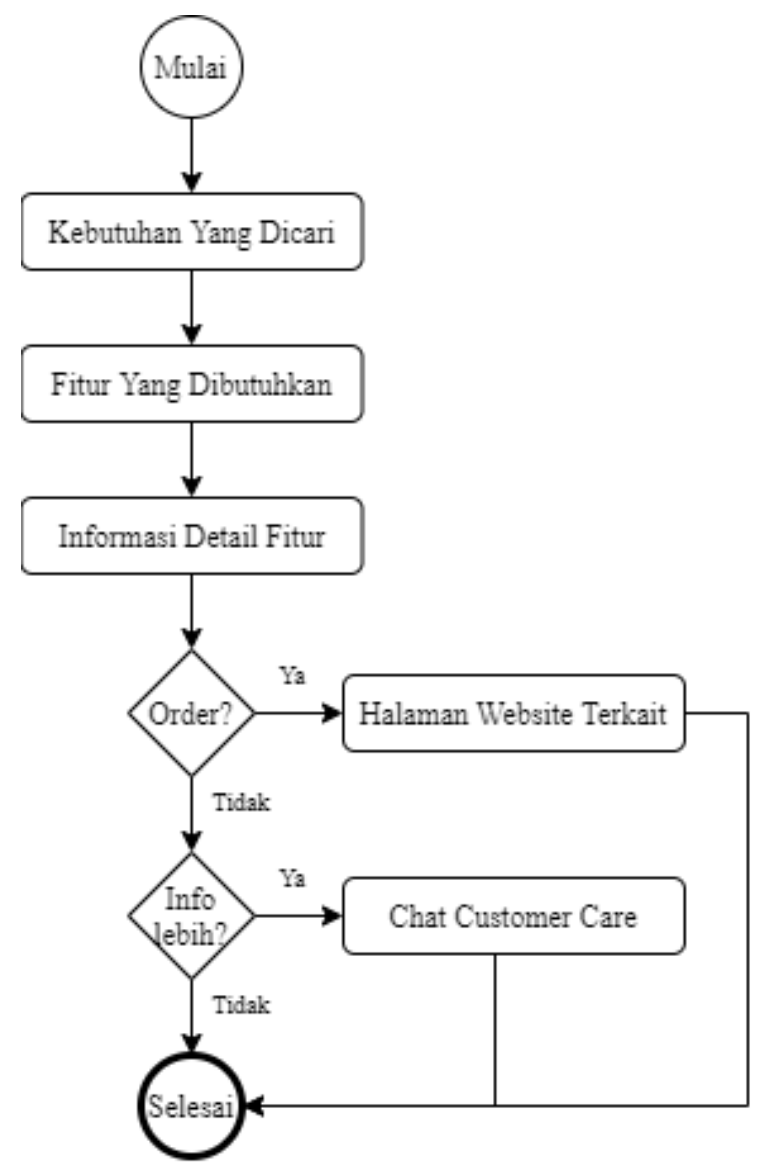

Gbr. 4 Alur Chatbot

Sebagai salah satu cara untuk meningkatkan kemungkinan pengguna website Gapura Studio membeli produk yang ditawarkan adalah dengan memberikan pelayanan melalui chatbot yang mampu memenuhi kebutuhan informasi yang di butuhkan pengguna. Chatbot akan berinteraksi dengan pengguna secara realtime. Alur yang dikembangkan pada gambar 4 sesuai dengan proses perjalanan pengguna saat melakukan pembelian produk seperti pada bisnis proses yang ada pada proses Penjualan Produk ditahap pemilihan produk. Selanjutnya adalah penerapan alur chatbot pada alat yang akan digunakan. Dalam penelitian ini peneliti menggunakan chatbot.com sebagai pengembang chatbot. Pada alat ini peneliti membuat alur chatbot seperti pada Gambar 5 dibawah ini: 


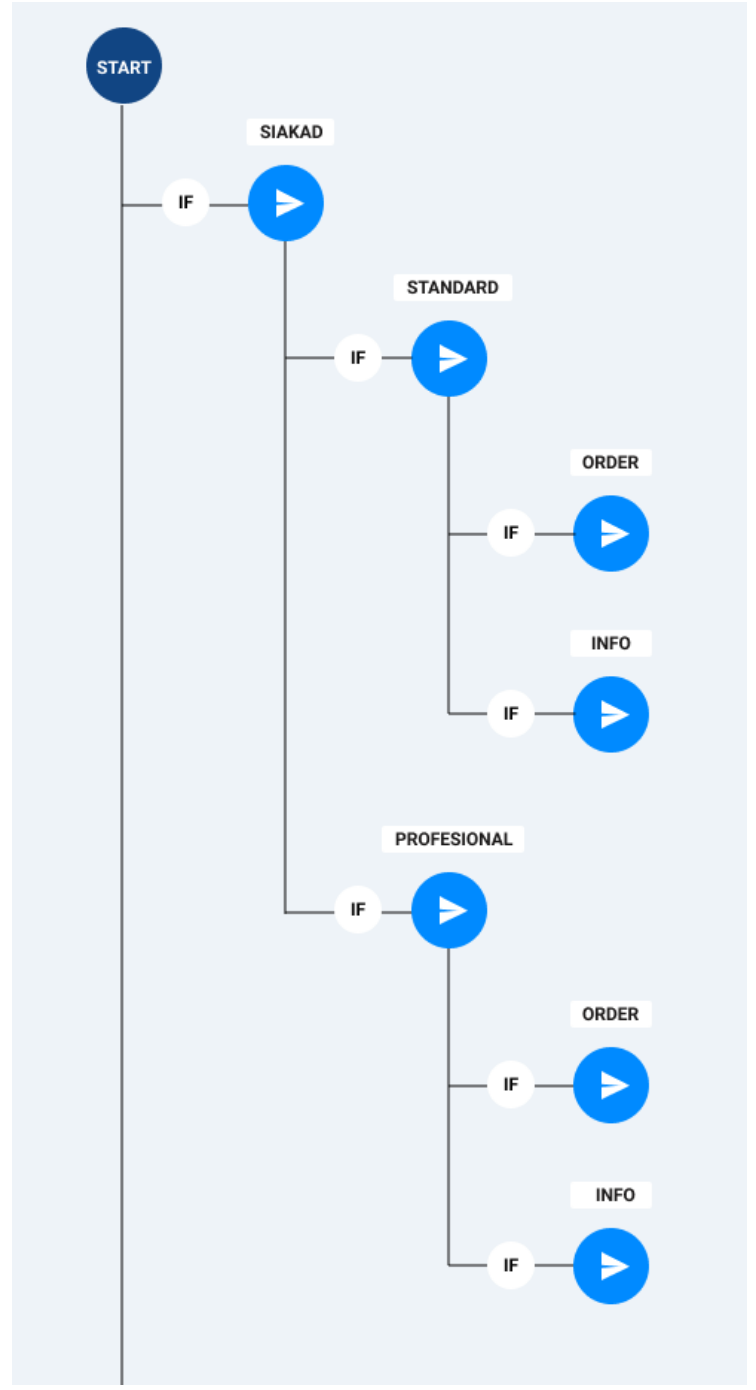

Gbr. 5 Implementasi Alur Chatbot

Pada Gambar 5 diatas menunjukkan alur chatbot yang diimplementasikan pada alat chatbot.com. Gambar tersebut menampilkan alur pada pemilihan salah satu produk Gapura Studio yaitu produk SIAKAD. Selanjutnya akan dibuat prototype interface dari hasil implementasi chatbot seperti pada Gambar 6 hingga 8 dibawah ini:

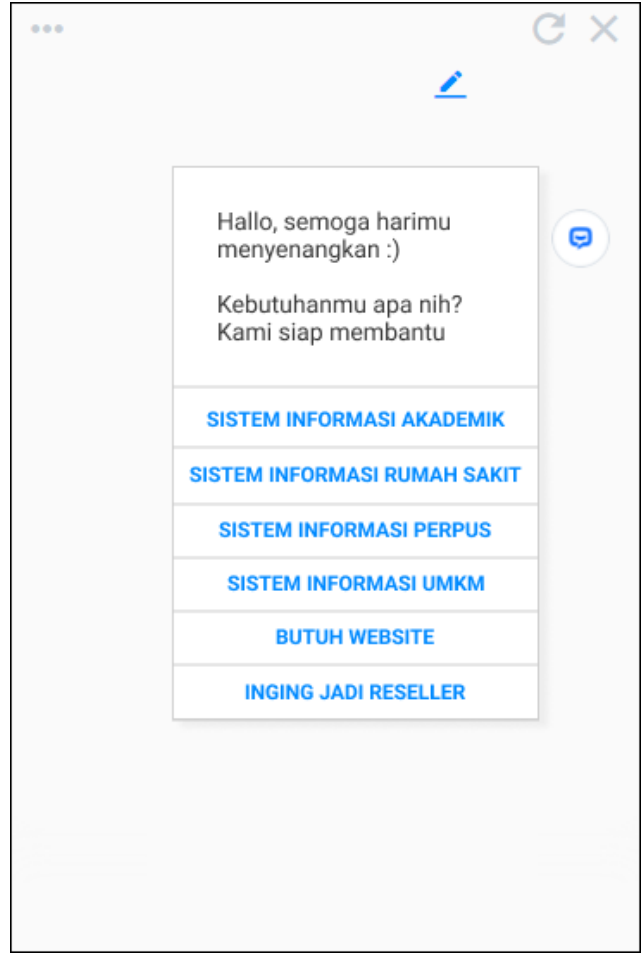

Gbr. 6 Prototipe Chatbot 1

Prototipe pada Gambar 6 ini menggambarkan interaksi chatbot dengan pengguna. Chatbot akan memberikan sapaan dan menanyakan kebutuhan yang sedang dicari sehingga pengguna website dapat diarahkan dengan produk yang sesuai dengan kebutuhan.

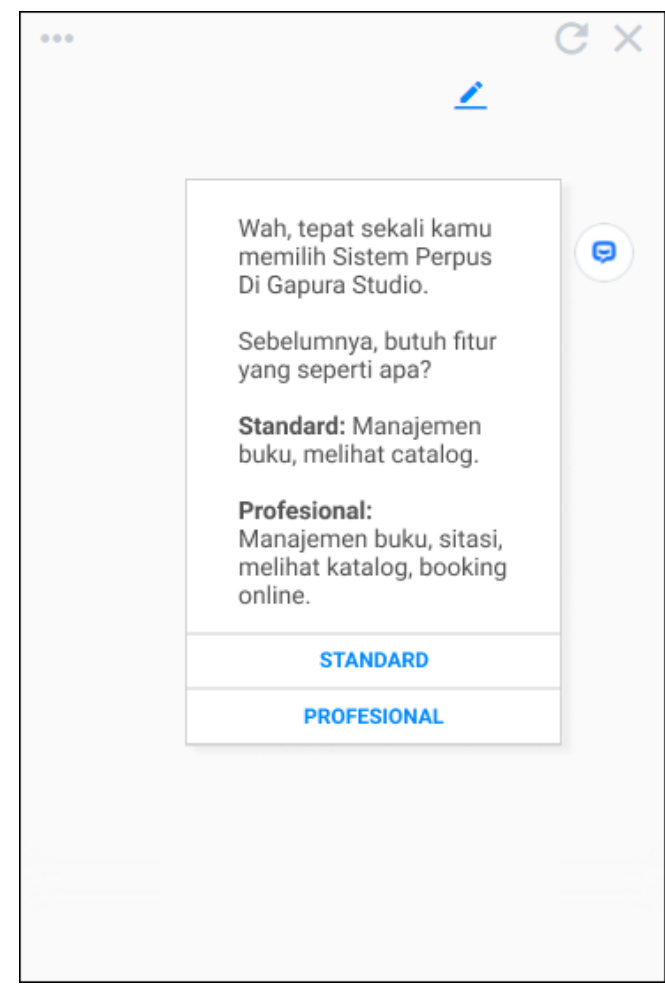

Gbr. 7 Prototipe Chatbot 2 
Pada Gambar 7, proses selanjutnya setelah pengguna memilih produk yang sesuai kebutuhan akan di arahkan lagi untuk memilih fitur dan spesifikasi produk yang dibutuhkan.

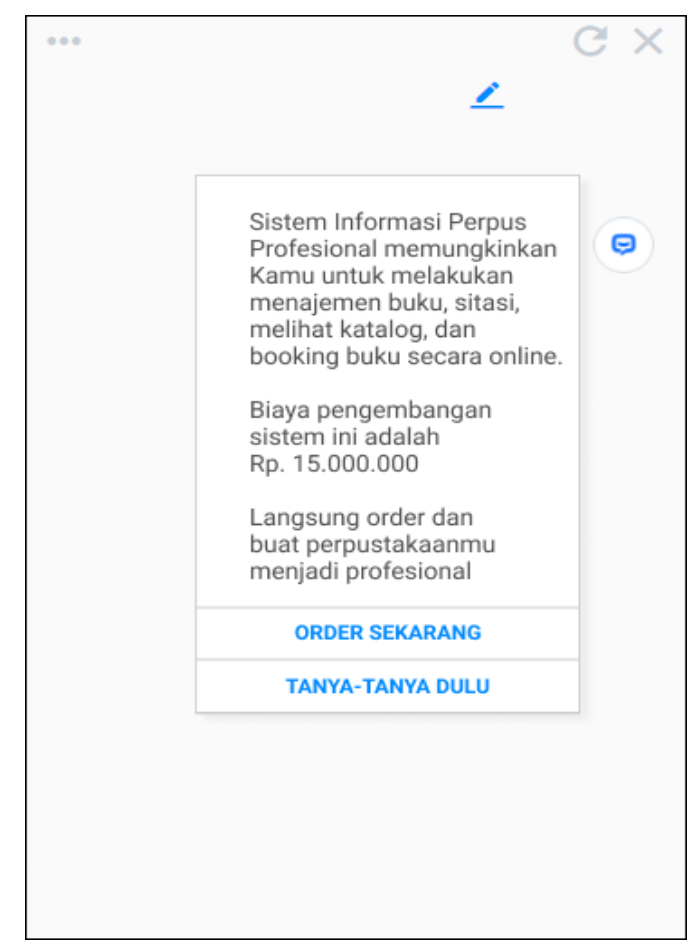

Gbr. 8 Prototipe Chatbot 3

Kemudian pada Gambar 8, pengguna akan di berikan penjelasan detail terkait produk yang dipilih sehingga dapat menjadi pertimbangan untuk membeli.

\section{KESIMPULAN}

Dalam penelitian ini penulis telah melakukan perancangan arsitektur enterprise pada perusahaan Gapura Studio. Perancangan yang dilakukan menggunakan kerangka kerja TOGAF ADM dengan tahapan preliminary, architecture vision, business architecture, dan system information architecture hingga menghasilkan blueprint perencanaan pengembangan sistem informasi yang menunjang proses bisnis Gapura Studio.

Selain itu, penelitian ini juga berhasil mengembangkan fitur chatbot yang harapan nya mampu menjadi solusi permasalahan awal website Gapura Studio dengan menambahkan interaksi berupa chatbot. Fitur chat dianggap mampu memberikan interaksi yang menyenangkan bagi pelanggan seperti yang terbukti pada penelitian sebelumnya bahwa mampu meningkatkan kepuasan [16]. Perancangan chatbot yang berhasil dikembangkan dalam penelitian ini berfokus pada aktivitas utama perusahaan yaitu penjualan produk sehingga juga dapat meningkatkan revenue dari perusahaan karena dengan memberikan detail informasi produk kepada pengguna website sesuai dengan alur proses perjalanan pengguna website akan memberikan perubahan faktor keputusan membeli.
Hal ini disebabkan adanya detail produk dan pelayanan yang mudah.

\section{REFERENSI}

[1] E. Cabrera and J. Holt, "An Evaluation of Website Usability for a Cover Crops Resource in the Southern Region," J. Appl. Commun., vol. 104, no. 1, 2020, doi: 10.4148/1051-0834.2305.

[2] M. Poulos, N. Korfiatis, and S. Papavlassopoulos, "Assessing stationarity in web analytics: A study of bounce rates," Expert Syst., vol. 37, no. 3, 2020, doi: 10.1111/exsy.12502.

[3] P. Smutny and P. Schreiberova, "Chatbots for learning: A review of educational chatbots for the Facebook Messenger," Comput. Educ., vol. 151, no. March, 2020, doi: 10.1016/j.compedu.2020.103862.

[4] F. Thaib and A. R. Emanuel, "Perancangan Enterprise Architecture UNIPAS Morotai Menggunakan TOGAF ADM," Teknika, vol. 9, no. 1, pp. 1-8, 2020, doi: 10.34148/teknika.v9i1.247.

[5] D. Rusli and Y. Bandung, "Designing an enterprise architecture (EA) based on TOGAF ADM and MIPI," 2017 Int Conf. Inf. Technol. Syst. Innov. ICITSI 2017 - Proc., vol. 2018Janua, pp. 38-43, 2017, doi: 10.1109/ICITSI.2017.8267915.

[6] S. D. Oktalia, R. N. Shofa, and R. Rianto, "Perencanaan Arsitektur SI/TI menggunakan Framework TOGAF (Studi Kasus: Dinas Perpustakaan dan Kearsipan Daerah Kota Tasikmalaya)," J. Buana Inform., vol. 10, no. 1, p. 63, 2019, doi: 10.24002/jbi.v10i1.1842.

[7] A. Y. Chandra, D. Kurniawan, and R. Musa, "Perancangan Chatbot Menggunakan Dialogflow Natural Language Processing (Studi Kasus: Sistem Pemesanan pada Coffee Shop)," J. Media Inform. Budidarma, vol. 4, no. 1, p. 208, 2020 doi: $10.30865 / \mathrm{mib}$.v4i1.1505.

[8] Y. Firmansyah and U. Udi, "Penerapan Metode SDLC Waterfall Dalam Pembuatan Sistem Informasi Akademik Berbasis Web Studi Kasus Pondok Pesantren Al-Habib Sholeh Kabupaten Kubu Raya, Kalimantan Barat," J. Teknol. dan Manaj. Inform., vol. 4, no. 1, 2017, doi: 10.26905/jtmi.v4i1.1605.

[9] M. Maskur, "Perancangan Chatbot Pusat Informasi Mahasiswa Menggunakan Aiml Sebagai Virtual Assistant Berbasis Web," Kinetik, vol. 1, no. 3, p. 123, 2016, doi: 10.22219/kinetik.v1i3.47.

[10] R. r. Benedictus, H. F. Wowor, and A. Sambul, "Rancang Bangun Chatbot Helpdesk untuk Sistem Informasi Terpadu Universitas Sam Ratulangi," J. Tek. Inform., vol. 11, no. 1, 2017, doi: 10.35793/jti.11.1.2017.16557.

[11] J. G. P. Negara and A. W. R. Emanuel, "Enterprise Architecture Design Strategies for UGK Using TOGAF ADM," no. October, 2020, doi: 10.2991/assehr.k.200529.103.

[12] R. E. Pariama, "Enterprise Arsitektur Planning (EAP) untuk Universitas Pattimura menggunakan TOGAF ADM," JATISI (Jurnal Tek. Inform. dan Sist. Informasi), vol. 7, no. 2, pp. 277288, 2020, doi: 10.35957/jatisi.v7i2.209.

[13] V. Soraya and W. S. Sari, "Perancangan Enterprise Architecture Sistem Informasi dengan Menggunakan Framework TOGAF ADM pada CV. Garam Cemerlang," JOINS (Journal Inf. Syst., vol. 4, no. 2, pp. 148-156, 2019, doi: 10.33633/joins.v4i2.3054

[14] H. Husain, P. N. Andono, and M. A. Soeleman, "Perspektif Baru Enterprise Architecture Pemerintahan Kota Mataram Berbasis TOGAF ADM," J. Matrik, vol. 16, no. 2, p. 76, 2017, doi: 10.30812/matrik.v16i2.6.

[15] S. Gupta, N. K. Malhotra, M. Czinkota, and P. Foroudi, "The local brand representative in reseller networks," J. Bus. Res., vol. 69, no. 12, pp. 5712-5723, 2016, doi: 10.1016/j.jbusres.2016.01.046.

[16] G. McLean and K. Osei-Frimpong, "Examining satisfaction with the experience during a live chat service encounterimplications for website providers," Comput. Human Behav., vol. 76, no. August, pp. 494-508, 2017, doi: 10.1016/j.chb.2017.08.005 